\title{
Stability of Film-Forming Dispersions: Affects the Morphology and Optical Properties of Polymeric Films
}

\author{
Maria Gabriela De Paola ${ }^{1}$, Rosy Paletta ${ }^{1}$, Catia Giovanna Lopresto ${ }^{1, *} \mathbb{C}$, Giuseppe Emanuele Lio ${ }^{2}($, \\ Antonio De Luca ${ }^{2}$ (D), Sudip Chakraborty ${ }^{1, *(\mathbb{D})}$ and Vincenza Calabrò ${ }^{1}$ (D) \\ 1 Department of Computer Engineering, Modeling, Electronics and Systems (D.I.M.E.S), University of Calabria, \\ I-87036 Rende, Italy; mgdep66@gmail.com (M.G.D.P.); rosypaletta9321@gmail.com (R.P.); \\ vincenza.calabro@unical.it (V.C.) \\ 2 Department of Physics, University of Calabria, and CNR-Nanotec, I-87036 Rende, Italy; \\ giuseppe.lio@unical.it (G.E.L.); antonio.deluca@fis.unical.it (A.D.L.) \\ * Correspondence: catialopresto@gmail.com (C.G.L.); sudip.chakraborty@unical.it (S.C.)
}

Citation: De Paola, M.G.; Paletta, R.; Lopresto, C.G.; Lio, G.E.; De Luca, A.; Chakraborty, S.; Calabrò, V. Stability of Film-Forming Dispersions: Affects the Morphology and Optical Properties of Polymeric Films. Polymers 2021, 13, 1464. https:// doi.org/10.3390/polym13091464

Academic Editor: Nathanael Guigo

Received: 7 April 2021

Accepted: 28 April 2021

Published: 1 May 2021

Publisher's Note: MDPI stays neutral with regard to jurisdictional claims in published maps and institutional affiliations.

Copyright: (c) 2021 by the authors. Licensee MDPI, Basel, Switzerland. This article is an open access article distributed under the terms and conditions of the Creative Commons Attribution (CC BY) license (https:// creativecommons.org/licenses/by/ $4.0 /)$.

\begin{abstract}
Starch-based films are promising alternatives to synthetic films in food packaging. They were widely studied in terms of mechanical and optical properties. In food packaging, optical properties are of great interest because ultra violet (UV-light) protection is strictly required. Nevertheless, the characterization of film-forming dispersions was poorly addressed, especially regarding its correlation with the film produced. In this work, we characterized film-forming dispersions at different compositions of starch and carboxymethyl cellulose (CMC) by Turbiscan. This instrument is based on multiple light scattering and gives significant information about the miscibility of polymers in the dispersed phase. Indeed, it identifies the phenomena of destabilization and phase separation before their visibility to the unaided eye. This work aimed to study whether the homogeneous/inhomogeneous morphology of films could be forecast by the analysis of profiles obtained in the dispersed phase. The films produced were investigated by optical microscopy and absorbance analysis. As the CMC fraction increased, Turbiscan showed reduced phase separation. This implies better miscibility of mixture components and higher gelification degree. The related film was more homogeneous and presented higher UV absorbance. Consequently, film-forming dispersions and optical properties of films are strictly correlated and Turbiscan-based analysis is very useful to investigate the dispersion stability and predict the film quality.
\end{abstract}

Keywords: starch-based films; carboxymethyl cellulose; film-forming dispersions; Turbiscan; characterization; optical properties

\section{Introduction}

Despite their excellent mechanical properties, fossil-derived plastic materials cause environmental pollution due to their non-biodegradability. Therefore, there is a growing interest in replacing them with compostable and non-polluting biopolymers, moreover in food packaging [1]. There are many other different polymers used for film formation for various industrial applications around the world [2,3], either in batch or in immobilized condition. Some polymeric membrane has also been used for recovery of reactive solvents or chemicals used in complex aqueous solutions [4,5]. Biopolymers can be produced from abundant, cheap, and renewable sources, and are good barriers for oxygen and carbon dioxide. The most studied biopolymers are carbohydrates, particularly starch.

Starch-based films are brittle, so plasticizers (e.g., glycerol) are usually used to enhance their flexibility [6]. Interactions among polymeric chains are needed to form films and are promoted by the addition of cross-linkers. Citric acid is commonly used as a cross-linker forming interactions between its carboxyl groups and hydroxyl groups in starch [7]. Citric acid strengthens the film structure, but it does not increase the film water permeability [8]. Starch-based films are generally prepared by the wet method. Starch and additives are 
dissolved in hot water to form a dispersion. This dispersion is poured and dried in a Petri dish or Teflon, until film formation occurs.

More interesting properties can be observed by introducing high molecular weight heteropolysaccharides into the dispersion, to improve mechanical properties and humidity control. Among them, carboxymethyl cellulose (CMC) has proved to be very promising. It is a non-toxic and non-allergenic ether cellulose and it can bind water, thanks to the high number of carboxyl and hydroxyl groups. CMC has a high viscosity and its chemical structure, which is similar to starch, limits miscibility problems in the initial dispersion [9]. The observable effects on films are the increase of tensile strength and the decrease of elongation [10].

Optical properties also are relevant for food packaging. Sometimes, a high degree of transparency is preferred for better visualization, but opacity helps to increase shelf life, protecting against incident light [11].

Generally, films are well characterized from a mechanical and optical point of view [12], but less attention is paid to characterizing the film-forming dispersions by the study of rheological properties [13] and stability. In literature, stability is evaluated in terms of zeta potential [14], because charges of polymer chains affect the kind of aggregation and, consequently, the microstructural network [15].

Turbiscan allows an in-depth characterization of film-forming dispersions, by visualization of the main phenomena of particle migration (sedimentation, creaming) and aggregation (flocculation, coalescence). This instrument, based on multiple light scattering, can calculate a stability index of dispersions (TSI, Turbiscan Stability Index) by comparing backscattering and transmission profiles during the time.

The Turbiscan equipment was used to investigate destabilization phenomena of inorganic phase change materials [16-18], but it is promising also in other dispersion-based applications.

When a film is formed from a polymeric dispersion, the first step of suspended particles coalescence is observed, followed by interactions among chains [15,19]. This starts the gelification process leading to a more stable dispersion, as observed in nano silica gelification [20].

The present work aims to study whether and how the characteristics of film-forming dispersions affect the morphology and optical properties of the films produced. Generally, the miscibility of polymers was studied on solid-state films by Fourier-transform infrared spectroscopy (FT-IR) analysis, X-ray diffraction, differential scanning calorimetry, light optical microscopy, and scanning electron microscopy [21]. Nevertheless, to the best of our knowledge, this correlation between the dispersion and the film produced has been never investigated in the literature.

Samples of three film-forming dispersions, based on starch-CMC, were characterized by Turbiscan, in terms of stability and destabilization phenomena to identify possible phase separation and evaluate the degree of miscibility among components already in the dispersed phase. Films were prepared from each dispersion by the wet method. Drying conditions were kept constant. The morphology of the obtained films was analyzed by optical microscope and the results were processed using Image J to define the degree of homogeneity.

Furthermore, light absorption tests were carried out on films in the UV area. Films used for food preservation, require no absorption in the UV area, especially in the case of foods with a significant amount of fats, because UV absorption is responsible for oxidative degradation [22].

\section{Materials and Methods}

\subsection{Materials}

Starch from potato and carboxymethyl cellulose CMC in different ratios was used as the main component for film preparation; sodium hexametaphosphate $65-70 \% \mathrm{P}_{2} \mathrm{O}_{5}$ basis, 
glycerol, citric acid, and distilled water were also used in different ratios. All chemicals were supplied by Sigma-Aldrich.

\subsection{Methods}

\subsubsection{Dispersion and Film Preparation}

Dispersions were prepared by the modified Ghanbarzadeh method [9]. Sodium hexametaphosphate is a non-toxic additive used in the food industry and it was added as a thickener. Glycerol and citric acid were added as plasticizer and cross-linker, respectively.

Three dispersions, named S, were prepared by stirring $5 \mathrm{~g}$ of starch, $2 \mathrm{~mL}$ of glycerol, $1 \mathrm{~g}$ of sodium hexametaphosphate, and $0.5 \mathrm{~g}$ of citric acid in $100 \mathrm{~mL}$ distilled water, firstly at room temperature for $5 \mathrm{~min}$ and then in a hot water bath at $90{ }^{\circ} \mathrm{C}$ for $30 \mathrm{~min}$.

Then, three different $\mathrm{CMC}$-based dispersions were prepared by stirring components at $75^{\circ} \mathrm{C}$ for $15 \mathrm{~min}$. The three dispersions named $\mathrm{CMC}_{1}, \mathrm{CMC}_{2}$, and $\mathrm{CMC}_{3}$ were prepared by adding, respectively, $0.5,0.75$, and $1 \mathrm{~g}$ of $\mathrm{CMC}$ in $75 \mathrm{~mL}$ of distilled water.

Finally, three dispersions were obtained by mixing two dispersions, one based on starch (the dispersion S) and another one based on CMC, as described in Table 1.

Table 1. Composition and preparation method of dispersions.

\begin{tabular}{|c|c|c|}
\hline Dispersion & Composition & Preparation \\
\hline$S$ & $\begin{array}{l}5 \text { g starch } \\
2 \mathrm{~mL} \text { glycerol } \\
1 \mathrm{~g} \text { sodium } \\
\text { hexametaphosphate } \\
0.5 \mathrm{~g} \text { citric acid } \\
100 \mathrm{~mL} \text { distilled water }\end{array}$ & $\begin{array}{l}5 \mathrm{~min} \text { at room temperature }+ \\
30 \mathrm{~min} \text { at } 90^{\circ} \mathrm{C}\end{array}$ \\
\hline $\mathrm{CMC}_{1}$ & $\begin{array}{l}0.5 \mathrm{~g} \mathrm{CMC} \\
75 \mathrm{~mL} \text { distilled water }\end{array}$ & $15 \mathrm{~min}$ at $75^{\circ} \mathrm{C}$ \\
\hline $\mathrm{CMC}_{2}$ & $\begin{array}{l}0.75 \mathrm{~g} \mathrm{CMC} \\
75 \mathrm{~mL} \text { distilled water }\end{array}$ & $15 \mathrm{~min}$ at $75^{\circ} \mathrm{C}$ \\
\hline $\mathrm{CMC}_{3}$ & $\begin{array}{l}1 \mathrm{~g} \mathrm{CMC} \\
75 \mathrm{~mL} \text { distilled water }\end{array}$ & $15 \mathrm{~min}$ at $75^{\circ} \mathrm{C}$ \\
\hline $\mathrm{S}-\mathrm{CMC}_{1}$ & $\mathrm{~S}+\mathrm{CMC}_{1}$ & $10 \mathrm{~min}$ at $75^{\circ} \mathrm{C}$ \\
\hline $\mathrm{S}-\mathrm{CMC}_{2}$ & $\mathrm{~S}+\mathrm{CMC}_{2}$ & $10 \mathrm{~min}$ at $75^{\circ} \mathrm{C}$ \\
\hline $\mathrm{S}-\mathrm{CMC}_{3}$ & $\mathrm{~S}+\mathrm{CMC}_{3}$ & $10 \mathrm{~min}$ at $75^{\circ} \mathrm{C}$ \\
\hline
\end{tabular}

Dispersions $\mathrm{S}-\mathrm{CMC}_{1}, \mathrm{~S}-\mathrm{CMC}_{2}$, and $\mathrm{S}-\mathrm{CMC}_{3}$ were cooled to $40^{\circ} \mathrm{C}$. From each of them, $25 \mathrm{~mL}$ were taken for Turbiscan analysis, and $70 \mathrm{~mL}$ were taken for the film preparation.

Films were prepared according to the thermal-induced phase separation (TIPS). An amount of $70 \mathrm{~mL}$ of each dispersion was poured onto a Petri dish (diameter $9 \mathrm{~cm}$, height $3 \mathrm{~cm}$ ) and placed in a forced ventilation oven at $60^{\circ} \mathrm{C}$ for $8 \mathrm{~h}$.

\subsubsection{Characterization of Dispersions}

The film-forming dispersions were characterized by Turbiscan (developed by Formulation, Smart Scientific Analysis) at $60^{\circ} \mathrm{C}$ for $8 \mathrm{~h}$. The Turbiscan equipment is based on multiple light scattering to identify the particles' migration and their size change in liquid dispersions. It is provided with two detectors, working in transmission (T) and backscattering (BS) modes. This makes possible the analysis of both transparent and opaque samples. When $\mathrm{T}$ is higher than $0.2 \%$ the instrument works in transmission mode, whereas a value of $\mathrm{T}$ lower than $0.2 \%$ indicates backscattering mode. The "Delta" mode facilitates the visualization of destabilization phenomena, by using the first scan as a reference and by amplifying variations. Results were compared with reference $\triangle B S$ profiles in the whole cell shown in Figure 1 and adapted from the instrument handbook. 


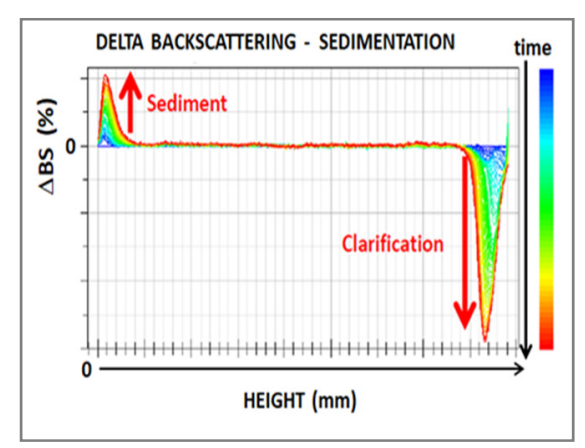

(a)

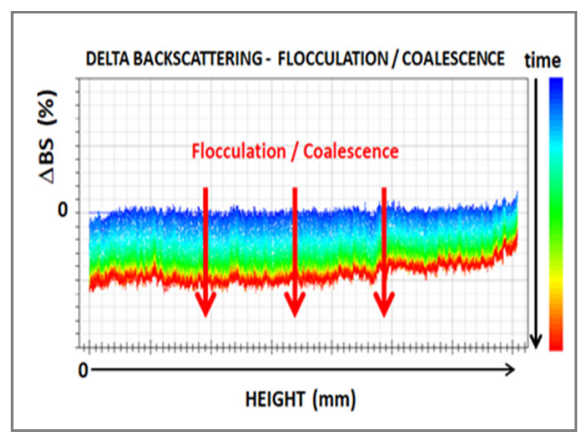

(b)

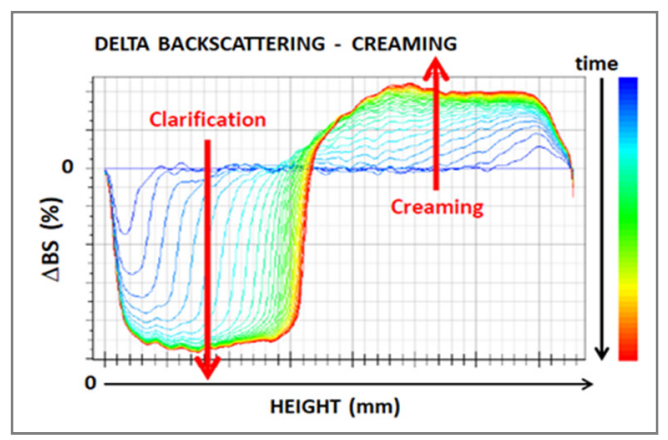

(c)

Figure 1. Main phenomena of destabilization in dispersions observed by Turbiscan analysis: (a) sedimentation; (b) flocculation/coalescence; and (c) creaming. (adapted from [16]).

Therefore, Turbiscan identifies possible coalescence phenomena before gelification. Besides, the formation of a gelified structure can be correlated with the system stabilization [20], by the variation of the Turbiscan stability index (TSI). The TSI value is calculated by the instrument by comparing each scan to the previous one, at a selected height, and dividing the result by the total height selected (Equation (1))

$$
\mathrm{TSI}=\sum_{\mathrm{I}} \frac{\sum_{\mathrm{h}}\left|\operatorname{scan}_{\mathrm{i}}(\mathrm{h})-\mathrm{scan}_{\mathrm{i}-1}(\mathrm{~h})\right|}{\mathrm{H}}
$$

The gelification degree is higher when the slop of the TSI vs. time curve decreases, because the system stability increases.

\subsubsection{Film Characterization}

Film thickness-The thickness of films was measured with a digital Borletti caliper, taking measurements in several places and calculating the average value.

Morphology-Samples were analyzed by optical microscope Leica DMRX (Zeiss) to characterize the film morphology. Magnification power used in the examination was $50 \times$. The microscope uses a white lamp in the entire visible range and the operative mode used was the reflection one. The microscope is equipped with a Canon 600D reflex camera with proper lens and mount for microscopic investigation. The scanned area has a total size of $40 \mu \mathrm{m} \times 100 \mu \mathrm{m}$, depending on the focal beam waist and charge-coupled device (CCD) sensor.

Light transmittance and opacity value-The absorbance analysis of samples was carried out by a dedicated spectroscopic system able to collect the transmitted signal through each sample. A Xenon lamp was used to produce white light radiation in a range from 250 to $1100 \mathrm{~nm}$; then, the sample was mounted on a holder that permits having three-axis movement, whereas two optical fibers, coupled with two GRIN (graded-index) lenses, are used to focus the white light on the sample and to collect the transmitted part of the signal. A spectrometer (Ocean Optics, USB-4000), working in a wavelength range 
from 250 to $1100 \mathrm{~nm}$ ), was used to measure the absorbed light, and returned its spectral behavior.

The "reference" signal in the spectroscopic measurements is acquired as a ratio between the white light of the Xenon lamp (shutter off) and the background signal (shutter on).

Besides, the film opacity was evaluated to ensure and validate the possibility of using films as a shelter from light (UV-Vis-NIR). Opacity is directly related to the intensity of light absorbed by the film at a particular wavelength. Opacity was calculated by dividing the absorption value at $600 \mathrm{~nm}$ by the film thickness according to [23] (Equation (2)).

$$
\text { Opacity }(\mathrm{O})=(\text { absorbance }(\lambda=600 \mathrm{~nm})) /(\text { thickness }(\mathrm{mm}))
$$

\section{Results and Discussion}

\subsection{Dispersions Characterization}

Since the transmission signal (T\%) was higher than $0.2 \%$ for all dispersion, the backscattering signal was not analyzed because it was due to internal reflections in cells $[24,25]$.

Data were reported in $\Delta \mathrm{T} \%$ mode to better visualize destabilization phenomena. It is evident in Figure 2 that transmission profiles shifted upwards over the whole length of samples. Therefore, coalescence was the main destabilization phenomenon and particle aggregates were formed during the analysis time. Peaks visible at the top and bottom of samples indicated the presence of creaming and sedimentation, respectively. Increasing $\mathrm{CMC}$ content led to reduced coalescence. Indeed, the $\Delta \mathrm{T} \%$ values of samples of $\mathrm{S}-\mathrm{CMC}_{1}$, $\mathrm{S}-\mathrm{CMC}_{2}$ and $\mathrm{S}-\mathrm{CMC}_{3}$ are 15, 10, and 5, respectively. Moreover, the peak width at the top and bottom of samples decreased when the amount of CMC increased, so that minor phase separation occurred.

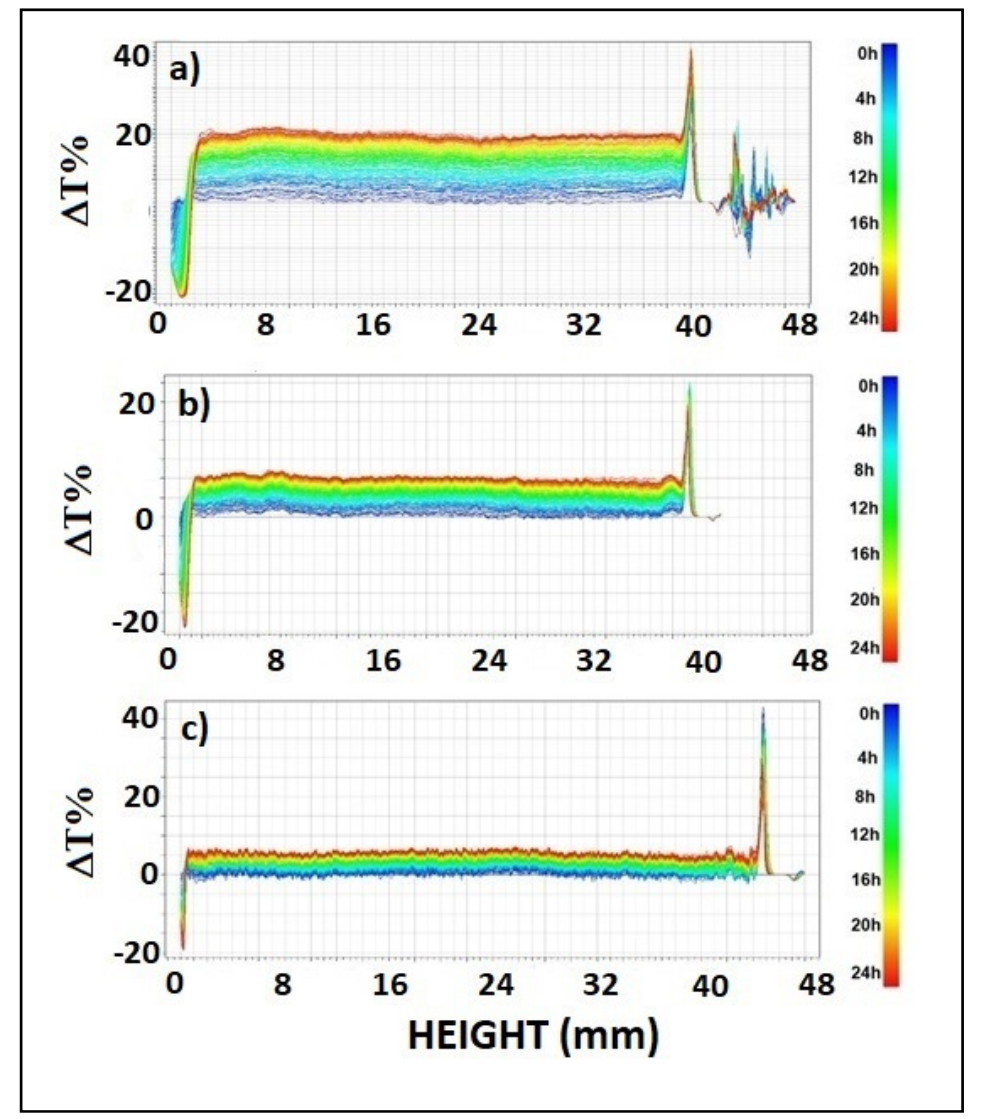

Figure 2. Profiles of Delta transmittance, $\Delta \mathrm{T}(\%)$, in each dispersion sample (analysis time: $24 \mathrm{~h}$ ) (a) $\mathrm{S}_{-} \mathrm{CMC}_{1}$, (b) $\mathrm{S}-\mathrm{CMC}_{2}$, and (c) $\mathrm{S}-\mathrm{CMC}_{3}$. 
The extent of phase separation was $6.58 \%, 5.43 \%$, and $3.32 \%$ (in terms of volume) in $\mathrm{S}-\mathrm{CMC}_{1}, \mathrm{~S}-\mathrm{CMC}_{2}$, and $\mathrm{S}-\mathrm{CMC}_{3}$, respectively. It is associated with the mutual solubility of components. Even small phase separation could affect the film quality by causing irregular portions. This was less evident in a film obtained from dispersion $\mathrm{S}_{-} \mathrm{CMC}_{3}$. Probably, the mixture starch $+\mathrm{CMC}+$ additives was not soluble at every composition.

The profiles of TSI over time are shown in Figure 3. The data were highly reproducible, with a negligible standard deviation.

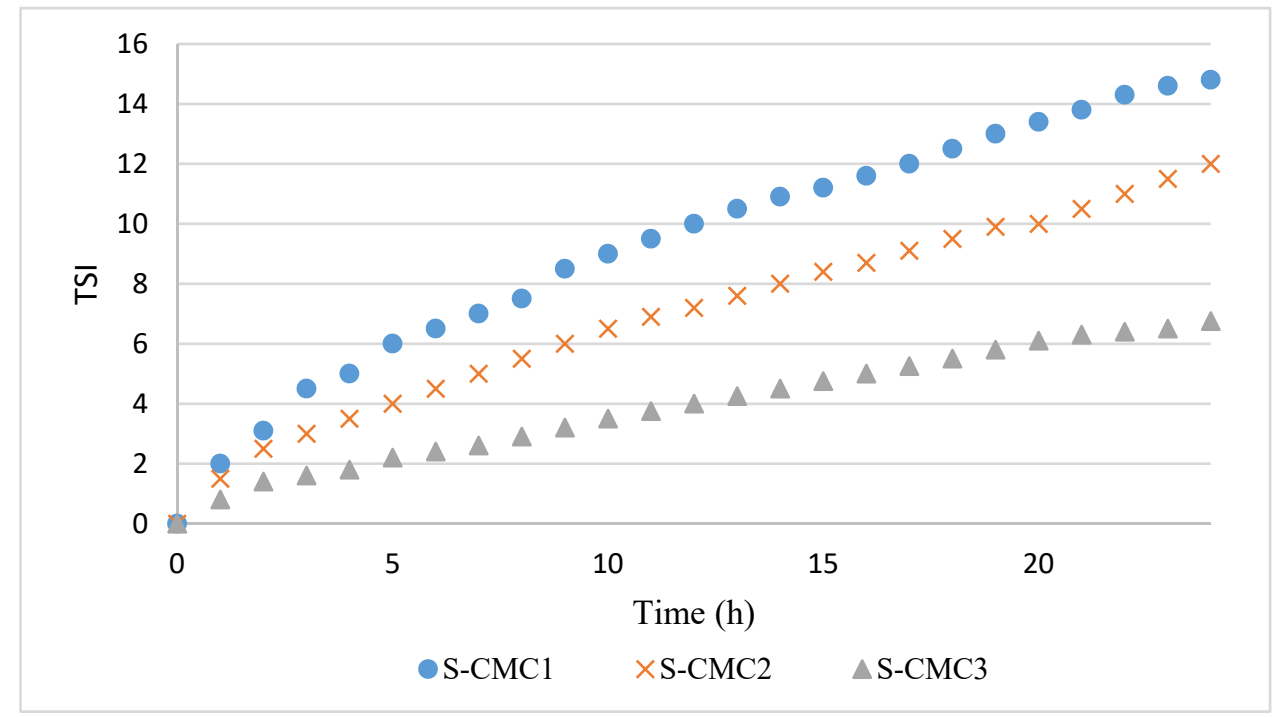

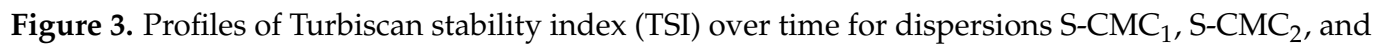
$\mathrm{S}-\mathrm{CMC}_{3}$.

The TSI profiles are coherent with $\Delta \mathrm{T} \%$. Indeed, the dispersion S-CM3 has the lowest phase separation corresponding to the lowest TSI values during the analysis.

In all curves, a significant variation of the slope was observed during the first $2 \mathrm{~h}$, corresponding with the first coalescence phase [16,20,26-28]. This slope change could be due to gelification beginning, when interactions among particles are formed before the film formation. After $2 \mathrm{~h}$, the dispersion $\mathrm{S}-\mathrm{CMC}_{3}$ presented the lowest slope, because of its higher stability and gelification degree.

The dispersion $\mathrm{S}-\mathrm{CMC}_{1}$ presented the widest sedimentation peak and the highest slope of TSI in the second phase. The width of sedimentation peak and slope of TSI decreased in dispersion $\mathrm{S}-\mathrm{CMC}_{2}$ and, further, in dispersion $\mathrm{S}-\mathrm{CMC}_{3}$. Systems are more stable with increasing CMC content. Probably, increasing CMC concentration led to higher mixture viscosity and reduced mobility of suspended particles.

\subsection{Film Characterization}

\subsubsection{Films Thickness}

The average value of film thickness, measured by a Borletti caliper, was equal to $0.35 \pm 0.01 \mathrm{~mm}$ for the $\mathrm{S}-\mathrm{CMC}_{1}$ film and $0.36 \pm 0.01 \mathrm{~mm}$ for both $\mathrm{S}-\mathrm{CMC}_{2}$ and $\mathrm{S}-\mathrm{CMC}_{3}$ films.

\subsubsection{Optical Microscope Analysis of Films}

The optical microscope analysis, carried out by a Zeiss microscope, gave information about the sample morphology and revealed a progressive increase of homogeneity from sample $\mathrm{S}-\mathrm{CMC}_{1}$ to sample $\mathrm{S}-\mathrm{CMC}_{3}$, as evident in Figure 4. 


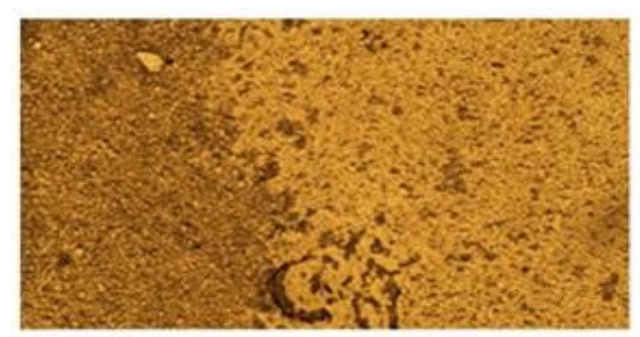

a) Film S-CMC

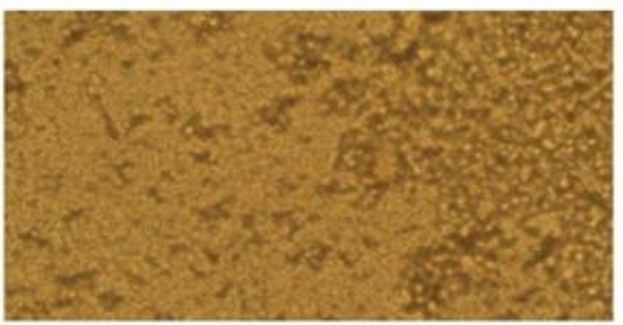

b) Film S-CMC

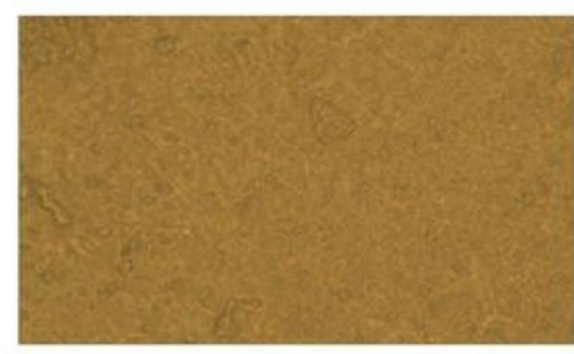

c) Film S-CMC

Figure 4. The micrographs show the surface morphology of the three produced films: (a) $\mathrm{S}-\mathrm{CMC}_{1}$; (b) $\mathrm{S}-\mathrm{CMC}_{2}$; and (c) $\mathrm{S}-\mathrm{CMC}_{3}$. The images have been collected using a Zeiss microscope in reflection mode using an input objective lens with a magnification of $50 \times$. Each image shows a $40 \times 100 \mu \mathrm{m}^{2}$ portion of film sample.

S-CMC 1 dispersion had the most evident phase separation and the highest variation of TSI; this affects the film produced, which was the most inhomogeneous in the microscopy analysis. Instead, $\mathrm{S}_{-} \mathrm{CMC}_{3}$ had no significant phase separation and the lowest variation of TSI, producing a homogeneous film. S-CMC 2 dispersion and the film obtained from it had intermediate behavior. The optical measurements provide qualitative information about the roughness of the sample surfaces. It is noticeable that the $\mathrm{S}-\mathrm{CMC}_{3}$ sample presented a surface that is almost flat without any inhomogeneity.

For a quantitative assessment of the inhomogeneity degree, open-source software for image processing (ImageJ) was used to obtain a full morphological characterization. Each picture was converted into grayscale. Then, an average of each surface profile was extracted by using the plot profile function, as reported in Figure 5a. Finally, the standard deviation of grey values was related to the inhomogeneity of films, as shown in Figure $5 b$.

\subsubsection{Optical Properties}

The optical properties of the obtained films were investigated by illuminating them with a focused white light beam. The spectroscopic system described in Section 2.2.3 was used to measure the absorbance (Abs) of samples, calculated as Abs $=1-\mathrm{T}-\mathrm{R}$, where $\mathrm{T}$ is the transmittance and $\mathrm{R}$ is the reflectance. Samples can scatter light, producing some light reflections. The absorbance of all samples was in the visible wavelength range $(\lambda=330-750 \mathrm{~nm})$. In particular, the $\mathrm{S}-\mathrm{CMC}_{2}$ and $\mathrm{S}-\mathrm{CMC}_{3}$ films exhibited high absorbance values in the UV range (black and blue lines, respectively). The film S-CMC 1 maintained the same trend, but a less intense signal (red line) was acquired. The spectral data are reported in the graphs of Figure 6. 

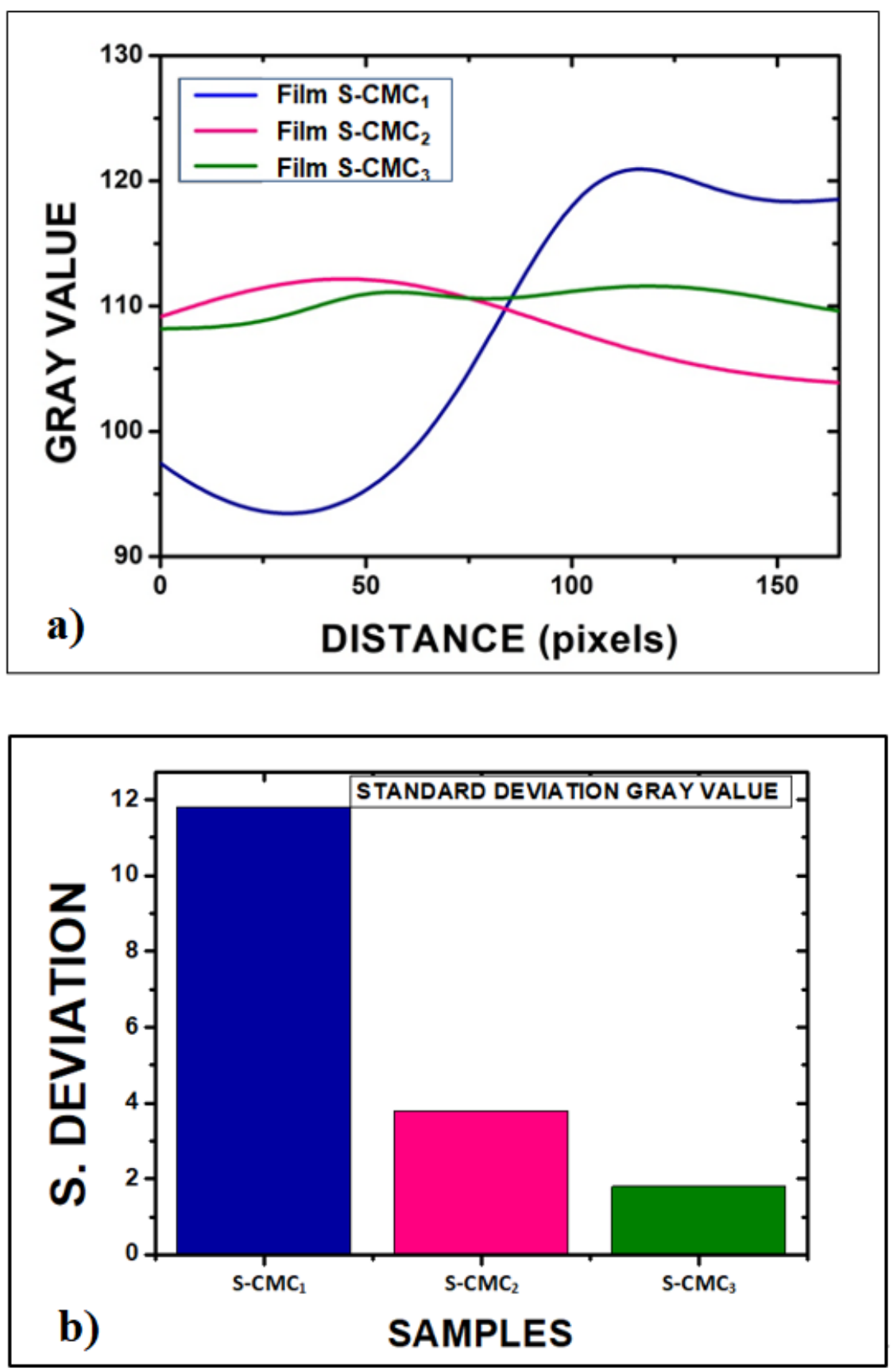

Figure 5. Quantitative assessment of the inhomogeneity degree of films: (a) Plot of the average of each sample profile function, after the optical image conversion into grayscale images by ImageJ software; (b) standard deviation of grey values related to inhomogeneity of films (11.8 for S-CMC ${ }_{1}$; 3.8 for $\mathrm{S}-\mathrm{CMC}_{2}$; and 1.8 for $\mathrm{S}-\mathrm{CMC}_{3}$ ).

Results confirmed the possible use of these films as a good alternative shield for food packaging. Since they presented high absorbance values in a large spectral range (UV-Vis-NIR), some of them could be a good absorptive layer. As reported in Section 2.2.1, the $\mathrm{S}-\mathrm{CMC}_{2}$ and $\mathrm{S}-\mathrm{CMC}_{3}$ films contain the highest quantities of $\mathrm{CMC}(0.75 \mathrm{~g}$ and $1 \mathrm{~g}$, respectively). This explains the lowest absorbance values of the $\mathrm{S}-\mathrm{CMC}_{1}$ film. The highest concentration $\left(\mathrm{S}-\mathrm{CMC}_{3}\right)$ represents the maximum absorption in the visible spectrum range, with a maximum in the UV-Vis range. 


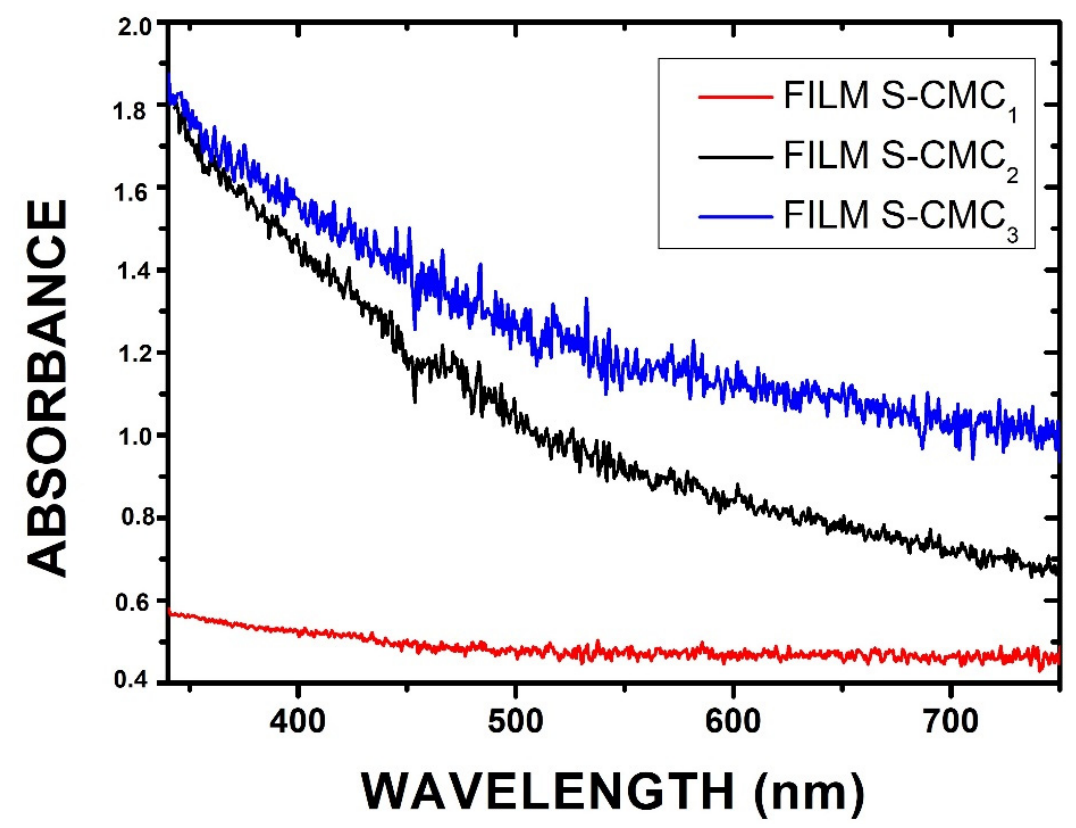

Figure 6. Absorbance spectra showing different behavior as a function of the concentration of CMC in the investigated films.

The opacity, evaluated by Equation (2), increased as CMC concentration increased (Figure 7). The $\mathrm{S}_{-} \mathrm{CMC}_{3}$ film showed the maximum opacity, according to the absorbance measurements.

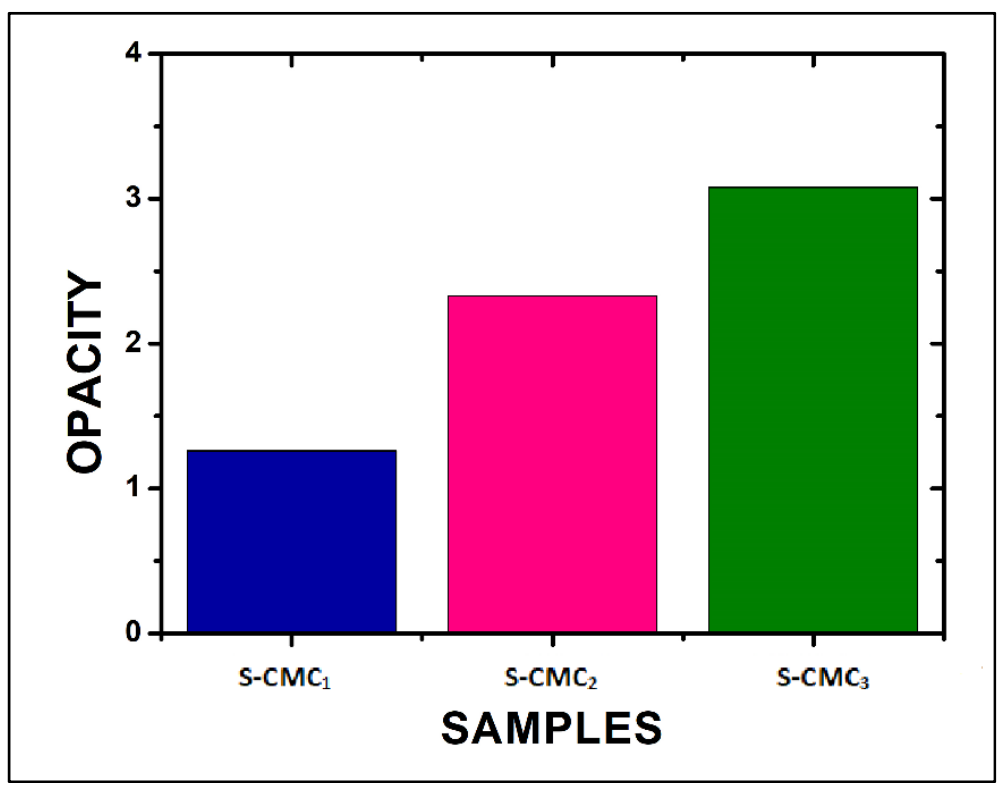

Figure 7. The opacity of the three films, evaluated at $600 \mathrm{~nm}$ by Equation (2).

\section{Conclusions}

Gelification needs coalescence to occur, but aggregates should not exceed a critical size. If this happens, sedimentation or creaming phenomena prevail over gelification, reducing the film quality. Results suggested that when coalescence was more intense (increasing $\Delta \mathrm{T}$ ), particles had a size such that migration phenomena (sedimentation, creaming) prevailed over gelification. Consequently, phase separation was observed. It caused inhomogeneity zones, which can be seen in the films produced. Furthermore, the increased dispersion stability after the coalescence step-that is evident in the reduced TSI slope during time-provided information about the gelification degree. 
The images acquired by the optical microscope showed the different morphologies of the three samples. S-CMC1 presented high roughness, whereas the S-CMC2 and SCMC3 films are more homogenous, as confirmed by the analysis of the greyscale images. Besides, the absorbance of the S-CMC1 film was lower than the other two films. A film that presents a high value of absorbance represents a good packing able to cover and protect the compound from ultraviolet light (UV). The fact that the absorbance is not zero at other wavelengths ensures that the film should also be used to absorb the visible near-infrared (Vis-NIR) range.

A strict correlation between film-forming dispersions and optical properties of films was observed and discussed. Lower phase separation and higher stability in dispersions lead to higher quality of films, showing greater homogeneity and absorbance in the UVVis-NIR spectrum. The most promising film was obtained from the S-CMC3 dispersion.

Consequently, Turbiscan-based analysis of dispersions is useful as a preliminary step to forecast the final film quality. This analysis could be performed to investigate films from any polymer. Moreover, it is possible to understand the effectiveness of additives as cross-linking agents and plasticizers and their influence on dispersion stability and destabilization phenomena.

Author Contributions: Material preparation, data collection, and analysis were performed by R.P., G.E.L., A.D.L. and. S.C.; formal analysis and discussion about results were performed by M.G.D.P. and C.G.L.; the first draft of the manuscript was written by M.G.D.P. and all authors commented on previous versions of the manuscript; writing - review, and editing were performed by C.G.L. and S.C., and V.C. supervised the work and reviewed the final version of the manuscript. V.C. was responsible for funding acquisition. All authors have read and agreed to the published version of the manuscript.

Funding: This work was supported by Regione Calabria (Italy) by the project POR CALABRIA FESR 2014/2020 Azione 1.2.2 "INNOVAZIONE NEL MONDO DEL CAFFE MONOPORZIONATOCOFFE PADS" (grant number: CUP J28C17000340006).

Institutional Review Board Statement: Not applicable.

Informed Consent Statement: Not applicable.

Data Availability Statement: The data presented in this study are available on request from the corresponding author.

Conflicts of Interest: All authors certify that they have no affiliations with or involvement in any organization or entity with any financial interest or non-financial interest in the subject matter or materials discussed in this manuscript.

\section{References}

1. Coppola, G.; Gaudio, M.T.; Lopresto, C.G.; Calabro, V.; Curcio, S.; Chakraborty, S. Bioplastic from Renewable Biomass: A Facile Solution for a Greener Environment. Earth Syst. Environ. 2021. [CrossRef]

2. Nasser, I.I.; Algieri, C.; Garofalo, A.; Drioli, E.; Ahmed, C.; Donato, L. Hybrid imprinted membranes for selective recognition of quercetin. Sep. Purif. Technol. 2016, 163, 331-340. [CrossRef]

3. Algieri, C.; Donato, L.; Bonacci, P.; Giorno, L. Tyrosinase immobilised on polyamide tubular membrane for the l-DOPA production: Total recycle and continuous reactor study. Biochem. Eng. J. 2012, 66, 14-19. [CrossRef]

4. Nasser, I.I.; Amor, F.I.E.H.; Donato, L.; Algieri, C.; Garofalo, A.; Drioli, E.; Ahmed, C. Removal and recovery of Ag(CN)2- from synthetic electroplating baths by polymer inclusion membrane containing Aliquat 336 as a carrier. Chem. Eng. J. 2016, 295, 207-217. [CrossRef]

5. Algieri, C.; Drioli, E.; Donato, L. Development of mixed matrix membranes for controlled release of ibuprofen. J. Appl. Polym. Sci. 2013, 128, 754-760. [CrossRef]

6. Müller, C.M.O.; Yamashita, F.; Laurindo, J.B. Evaluation of the effects of glycerol and sorbitol concentration and water activity on the water barrier properties of cassava starch films through a solubility approach. Carbohydr. Polym. 2008, 72, 82-87. [CrossRef]

7. Ghanbarzadeh, B.; Almasi, H.; Entezami, A.A. Improving the barrier and mechanical properties of corn starch-based edible films: Effect of citric acid and carboxymethyl cellulose. Ind. Crops Prod. 2011, 33, 229-235. [CrossRef]

8. Reddy, N.; Yang, Y. Citric acid cross-linking of starch films. Food Chem. 2010, 118, 702-711. [CrossRef]

9. Ghanbarzadeh, B.; Almasi, H.; Entezami, A.A. Physical properties of edible modified starch/carboxymethyl cellulose films. Innov. Food Sci. Emerg. Technol. 2010, 11, 697-702. [CrossRef] 
10. Tongdeesoontorn, W.; Mauer, L.J.; Wongruong, S.; Sriburi, P.; Rachtanapun, P. Effect of carboxymethyl cellulose concentration on physical properties of biodegradable cassava starch-based films. Chem. Cent. J. 2011, 5, 1-8. [CrossRef] [PubMed]

11. Domene-López, D.; García-Quesada, J.C.; Martin-Gullon, I.; Montalbán, M.G. Influence of starch composition and molecular weight on physicochemical properties of biodegradable films. Polymers (Basel) 2019, 11, 1084. [CrossRef] [PubMed]

12. Ma, X.; Chang, P.R.; Yu, J. Properties of biodegradable thermoplastic pea starch/carboxymethyl cellulose and pea starch/microcrystalline cellulose composites. Carbohydr. Polym. 2008, 72, 369-375. [CrossRef]

13. Peressini, D.; Bravin, B.; Lapasin, R.; Rizzotti, C.; Sensidoni, A. Starch-methylcellulose based edible films: Rheological properties of film-forming dispersions. J. Food Eng. 2003, 59, 25-32. [CrossRef]

14. Bonilla, J.; Atarés, L.; Vargas, M.; Chiralt, A. Properties of wheat starch film-forming dispersions and films as affected by chitosan addition. J. Food Eng. 2013, 114, 303-312. [CrossRef]

15. Chakraborty, S.; Pal, U. Towards growth and sustainable researches in phase change materials. J. Phase Chang. Mater. 2021, 11. Available online: https://j-pcm.org/index.php/jpcm/article/view/9 (accessed on 29 April 2021).

16. Sabbah, M.; Esposito, M. Insight into Zeta Potential Measurements in Biopolymer Film Preparation. J. Biotechnol. Biomater. 2016, 6, 2-4. [CrossRef]

17. De Paola, M.G.; Arcuri, N.; Calabrò, V.; De Simone, M. Thermal and stability investigation of phase change material dispersions for thermal energy storage by T-history and optical methods. Energies 2017, 10, 354. [CrossRef]

18. De Paola, M.G.; Lopresto, C.G.; Arcuri, N.; Calabrò, V. Crossed analysis by T-history and optical light scattering method for the performance evaluation of Glauber's salt-based phase change materials. J. Dispers. Sci. Technol. 2020, 1-9. [CrossRef]

19. De Paola, M.G.; Lopresto, C.G.; Arcuri, N.; Calabrò, V. T-history method: The importance of the cooling chamber to evaluate the thermal properties of Glauber's salt-based phase change materials. Meas. Sci. Technol. 2021, 32, 35601. [CrossRef]

20. Felton, L.A. Mechanisms of polymeric film formation. Int. J. Pharm. 2013, 457, 423-427. [CrossRef]

21. Boul, P.J.; Ye, A.; Pang, X.; Goel, V.; Eoff, L.; Reddy, B.R. Nanosilica-based Conformance Gels. In Proceedings of the SPE European Formation Damage Conference and Exhibition, Budapest, Hungary, 3-5 June 2015; Society of Petroleum Engineers: Richardson, TX, USA, 2015.

22. Soliman, E.A.; Furuta, M. Influence of Phase Behavior and Miscibility on Mechanical, Thermal and Micro-Structure of Soluble Starch-Gelatin Thermoplastic Biodegradable Blend Films. Food Nutr. Sci. 2014, 5, 1040-1055. [CrossRef]

23. Dick, M.; Costa, T.M.H.; Gomaa, A.; Subirade, M.; Rios, A.D.O.; Flôres, S.H. Edible film production from chia seed mucilage: Effect of glycerol concentration on its physicochemical and mechanical properties. Carbohydr. Polym. 2015, 130, 198-205. [CrossRef]

24. Peng, Y.; Wu, Y.; Li, Y. Development of tea extracts and chitosan composite films for active packaging materials. Int. J. Biol. Macromol. 2013. [CrossRef] [PubMed]

25. TURBISCAN. The Reference for Stability Analysis. Available online: https://particular.ie/brochures/supplier_brochures_pdf/ turbiscan_brochure.pdf (accessed on 20 April 2021).

26. Multiple Light Scattering. Available online: http://dafratec.com/wp-content/uploads/2020/11/Turbiscan_Tecnico-Lab.pdf (accessed on 20 April 2021).

27. De Paola, M.G.; Lopresto, C.G. Waste oils and their transesterification products as novel bio-based phase change materials. J. Phase Chang. Mater. 2021, 1. Available online: https://j-pcm.org/index.php/jpcm/article/view/6 (accessed on 29 April 2021).

28. Algieri, C.; Chakraborty, S.; Pal, U. Efficacy of Phase Inversion Technique for Polymeric Membrane Fabrication. J. Phase Chang. Mater. 2021, 1. Available online: https://j-pcm.org/index.php/jpcm/article/view/10 (accessed on 29 April 2021). 